\title{
CITIZENS UNITED Y LA FINANCIACIÓN DE LAS CAMPAÑAS ELECTORALES EN EL DERECHO NORTEAMERICANO*
}

\author{
ANA VALERO HEREDIA \\ Profesora Contratada Doctora de Derecho Constitucional \\ Universidad de Castilla-La Mancha
}

\begin{abstract}
SUMARIO
I. Introducción.

II. Estudio de la legislación norteamericana en materia de financiación de las campañas electorales.

III. La jurisprudencia de la Corte Suprema norteamericana en materia de financiación de las campañas electorales con anterioridad a Citizens United.

IV. Citizens United v. Federal Election Comission: La financiación corporativa de las campañas electorales ¿ejercicio de la libertad de expresión de las empresas?
\end{abstract}

\section{INTRODUCCIÓN.}

Basta realizar un seguimiento de las actuales elecciones primarias del Partido Republicano para darse cuenta de que ésta va a ser una campaña electoral distinta en Estados Unidos. Tras la celebración de las cuatro primeras citas electorales en la carrera republicana, algunos ya se atreven a afirmar que ésta, quizá, sea la campaña electoral más agresiva, oscura y sucia de la historia, a la vez que la más cara, con diferencia ${ }^{1}$.

La sentencia de la Corte Suprema norteamericana, pronunciada en el Caso Citizens United v. Federal Electoral Commission, de febrero de $2010^{2}$, abrió la puerta de las campañas

* El presente artículo fue elaborado en el marco de una estancia de investigación realizada en la Universidad Northwestern Law School de Chicago bajo la dirección del Catedrático de Derecho Constitucional Mr. Robert W. Bennet en el verano de 2010. A él y al Magistrado del Tribunal Supremo y Catedrático de Derecho Constitucional Luis María Díez-Picazo les debo que este trabajo vea la luz.

1 «El precio de la Casa Blanca», El Periódico, 2 de febrero de 2012, http://www.elperiodico.com/es/noticias//precio-casa-blanca-1378548

2558 U.S. 50 Citizens United v. Federal Electoral Commission (2010). 
electorales estadounidenses a donaciones ilimitadas de individuos, empresas y sindicatos a través de la creación de grupos paralelos a las campañas de los candidatos, llamados super comités de acción política o Super PACs.

Si se observan los anuncios de campaña que se emitieron, por ejemplo, en Florida antes de la celebración de las elecciones primarias, es fácil reconocer que todos ellos tenían un carácter negativo y de ataque al candidato opositor. Pero lo más relevante radica en que la elaboración de tales anuncios no se ha llevado a cabo por las campañas de los contrincantes, Mitt Romney, el ganador, o Newt Gingrich, el devastado segundo, sino por Restore Our Future y Winning our Future, los Super PACs que, respectivamente, les apoyan. Y no es difícil darse cuenta de que la contundente victoria de Romney tiene que ver con su propia campaña, la mejor financiada entre las de los cuatro aspirantes republicanos.

La sentencia de la Corte Suprema norteamericana, pronunciada en el Caso Citizens United v. Federal Electoral Commission, de febrero de 2010, pone en evidencia que los Estados Unidos de América siguen siendo uno de los lugares más idóneos para estudiar el nivel de salud del que goza el sistema democrático ${ }^{3}$. Principios consustanciales a la idea misma de democracia como el de igualdad en la participación de los individuos en la vida pública ${ }^{4}$, o la libertad de expresión, han sido evocados para declarar inconstitucional cualquier límite que se imponga a la facultad de las empresas de destinar dinero corporativo a la financiación de las campañas electorales.

En palabras de Ronald Dworkin, ninguna decisión de la Corte Suprema norteamericana ha generado una hostilidad tan explícita entre los tres poderes del sistema democrático norteamericano como Citizens, provocado una fuerte convulsión en el sistema legal norteamericano y conduciendo a una confrontación pública sin precedentes entre el Presidente del Gobierno y los Magistrados de la Corte, hecha pública en el discurso presidencial sobre el estado de la Unión 5 .

Todo comenzó en enero de 2008, cuando Citizens United, una organización sin ánimo de lucro de tendencia conservadora, emitió un amplio documental sobre la entonces senadora y candidata a las primarias Hillary Clinton. Tras su proyección en pocas salas cinematográficas, los editores decidieron aumentar su distribución a través de un sistema de vídeo «on demand» que permitía a los espectadores ver el programa en cualquier momento. La Comisión Federal Electoral prohibió dicha distribución por ser contraria a la Bipartisan Campaign Reform Act, de 27 de marzo de 2002, decisión que fue confirmada por el Tribunal Federal del Distrito de Columbia. Una vez en el Tribunal Supremo, éste ha emitido una Sentencia de cinco votos a favor — los de la mayoría conservadora- y

3 Cuando hace más de 150 años Alexis de Tocqueville publicó La democracia en América, afirmó con rotundidad que los Estados Unidos de aquella época eran el mejor sitio para estudiar a la democracia, la forma de gobierno cuyo advenimiento parecía inevitable en el mundo occidental.

4 Véase John RAWLS: A Theory of Justice, Harvard University Press, 1971, págs. 60-65.

5 R. DWORKIN: «The decision that threatens democracy», http://www.nybooks.com/articles/archives/2010/may/13/decision-threatens-democracy/. El Presidente de los Estados Unidos, Barack Obama, no tardó en reaccionar frente al fallo de la Corte emitido en Citizens, señalando que esta resolución fortalece más los intereses de los poderosos y de los grupos de presión de Washington, como petroleras, compañías de seguros y bancos, mientras se debilita a «tantos ciudadanos de a pie que hacen pequeñas contribuciones para apoyar a los candidatos preferidos». Además, ha ordenado a su Administración que estudie con el Congreso la posibilidad de rehacer la normativa sobre financiación de las campañas. 
cuatro en contra que revisa a fondo la doctrina jurisprudencial sobre la financiación de las campañas electorales en Estados Unidos hasta el punto de anular, por inconstitucionales, dos importantes precedentes.

El presente estudio pretende contra argumentar los fundamentos jurídicos en los que se asienta el fallo, no sin antes exponer cuáles son las bases legislativas y jurisprudenciales sobre las que se ha establecido hasta el momento el sistema norteamericano de financiación de las campañas electorales.

\section{ESTUDIO DE LA LEGISLACIÓN NORTEAMERICANA EN MATERIA DE FINANCIACIÓN DE LAS CAMPAÑAS ELECTORALES}

El binomio «dinero-política» no sólo es antiguo sino que es, quizá, tan necesario como conflictivo. Desde la aprobación en Gran Bretaña, en el año 1883, de la primera normativa de la época moderna en materia de financiación de la política, los intentos de disciplinar tal binomio han sido una constante en los distintos ordenamientos jurídicos de los sistemas democráticos. Podría decirse que la financiación de la política es instrumental para la consolidación de una democracia sostenible ${ }^{6}$.

La actividad de los partidos políticos en el seno de los regímenes democráticos requiere de ingentes recursos económicos. Si a ello sumamos la necesidad de financiar las campañas electorales y las actividades conexas a las mismas, la dependencia entre política y dinero se hace más que evidente. En este contexto, resulta imprescindible la adopción de normas que regulen la financiación de unos y otras que, por un lado, mantengan intactos los valores fundamentales de la democracia - tales como el principio de igualdad, la libertad de los electores, la autonomía de los electos o la libertad de expresión de los primeros y la libertad de expresión e información de los segundos-; y que, por otro, eviten exponer el sistema democrático a fenómenos degenerativos que puedan socavar sus propios pilares - tales como el clientelismo, la corrupción o la financiación interesada de candidatos y campañas por parte de grupos de poder que traten de en incidir en el proceso de formación de la voluntad política-.

\section{Principales rasgos del modelo de financiación de las Campañas ELECTORALES EN ESTADOS UNIDOS}

Debe tenerse en cuenta como punto de partida, que el estado de la legislación norteamericana en materia de campañas electorales hasta el pronunciamiento del Tribu-

6 Inglaterra fue el primer país que optó por la vía de limitar los gastos de los candidatos cuando, en 1883, aprobó la Corrupt and Ilegal Practices Act, ley que ha constituido hasta nuestros días la espina dorsal de la legislación británica sobre los aspectos económicos de las campañas. Esa legislación, reforzada por medidas posteriores, como la Representation of the People Act, de 1918, fue posteriormente incorporada por los Estados Unidos, país en que la vigencia de las medidas limitadoras de los gastos electorales de los candidatos tendría una evolución marcada por recurrentes derogaciones y recuperaciones. Véase R. BLANCO VALDÉS: «La problemática de la financiación de los partidos políticos en España: regulación jurídica y propuestas de reforma», REP (Nueva Época), núm. 87, enero-marzo, 1995, pág. 170. 
nal Supremo en el caso Citizens de 2010 y, en especial, lo referente a su financiación, al control de los gastos y al uso de los medios de comunicación, se explica a partir de ciertos hechos especialmente clamorosos acaecidos en la historia de la política norteamericana, como el caso Watergate. Y que los sucesivos intentos de regular esta materia han encontrado como principales escollos la propia naturaleza geográfica del país y el diseño mismo de las campañas electorales estadounidenses. Baste señalar a este último respecto que, por ejemplo, la campaña electoral presidencial se desarrolla sobre un territorio y frente a una población de dimensiones continentales, lo que inevitablemente exalta los costes y hace que el contacto directo entre candidato y elector sea más bien atípico. A ello debe sumarse el hecho de que nos encontramos ante una campaña electoral que dura como mínimo un año, lo que genera, nuevamente, que los costes se incrementen exponencialmente ${ }^{7}$.

El modelo de financiación de las campañas electorales en Estados Unidos tiene dos características que lo particularizan. La primera, que las normas que lo regulan se aplican principalmente a los candidatos y no a los partidos políticos a los que éstos pertenecen $^{8}$, y la segunda, que a pesar de que existen fuentes de financiación pública y privada, éstas últimas integran la primordial fuente de ingresos de los candidatos?

Los Estados Unidos fueron uno de los primeros países en adoptar una normativa reguladora de las campañas electorales en el ámbito federal. La primerísima norma en la materia se remonta a los tiempos de Theodore Roosevelt, que indujo al Congreso a adoptarla en 1907. Se trata de la llamada Tillman Act que se han mantenido en vigor, con varias modificaciones, hasta el 1966. Esta ley tenía la finalidad de limitar la influencia desproporcionada de las acumulaciones de riqueza y de los intereses particulares sobre el proceso electoral, además de tratar de desincentivar los abusos estableciendo obligaciones de transparencia. Asimismo, la experiencia norteamericana es primigenia en la adopción de normas destinadas a la limitar los gastos de los candidatos y de los partidos en las elecciones y a conseguir la limitación o la prohibición de determinadas contribuciones destinadas a las organizaciones partidistas. Así, desde 1939 han estado vigentes tales lími-

7 Para un estudio general sobre la legislación relativa a las campañas electorales en Estados Unidos, véase D. HAYS LOWENSTEIN, R. L. HASEN y D. P. TOKAJI: Election Law, Carolina Academic Press, 2010, págs. 549-577.

El montante de dinero destinado a la financiación de las campañas electorales en Estados Unidos se ha incrementado considerablemente y progresivamente en cada periodo desde los setenta hasta la actualidad. A este respecto son significativas las siguientes cifras: de los 540 millones de dólares gastados en las elecciones de 1976, se pasa a 4,2 billones de dólares en las elecciones de 1996. Véase a este respecto H. E. ALEXANDER: «Spending in the 1996 Elections», en J. C. GREEN, Ed.: Financing the 1996 Elections, M. E. Sharpe, Armonk, Nueva York, 1999.

8 En Estados Unidos los partidos políticos tienen una importancia secundaria frente a los candidatos. Este es el motivo por el que todas las normas que a lo largo de su historia han regulado la financiación de la campaña electoral, desde el siglo XIX, han tenido como objetivo primordial fijar las reglas que debían cumplir los candidatos, no los partidos. Puede verse un estudio en profundidad sobre el papel de los partidos políticos en el sistema político norteamericano en Daniel HAYS LOWESTWEIN, Richard L. HASEN y Daniel P. TOKAJI: Election Law, Carolina Academic Press, 2010, págs. 417-450.

9 K.H. NASSMACHER, «Party funding in Continental Western Europe», en VVAA, Funding of Political Parties and Election Campaigns, International Idea, Estocolmo, Suecia, 2003, pág. 33; S. SÁNCHEZ GONZÁLEZ, «La financiación de los partidos políticos en los Estados Unidos», en Teoría y Realidad Constitucional, núm. 6, 2000, págs. 72-73. 
tes, considerados compatibles con la Constitución por el Tribunal Supremo en 1976. El modelo norteamericano de regulación de la financiación de las campañas electorales ha sido denominado por la doctrina como «modelo fundado sobre la disciplina diversificada», habida cuenta de su larga tradición normativa federal dirigida a regular la materia ${ }^{10}$.

La era moderna de la regulación de las campañas electorales en Estados Unidos comienza a nivel federal después del escándalo del Watergate con la aprobación de la Federal Election Campaign Act Amendments (Ley de Campañas Electorales Federales) de 1971, FECA, que define las bases de la reglamentación de la financiación de las campañas electorales y que fija las reglas en materia de: divulgación de los recursos de los candidatos, topes máximos de las contribuciones electorales y limitaciones de los gastos de campaña ${ }^{11}$.

El 15 de octubre de 1974, el Congreso reformó la FECA, fijando la financiación pública de las diferentes etapas de la elección presidencial — primarias, convenciones de los partidos políticos y elección general — con el sistema de matching funds — en virtud del cual se le otorga al candidato el doble de la suma que recibió de donantes privados a condición de que cumpla determinados requisitos- Esta ley también creó la Federal Election Commission (Comisión Electoral Federal), FEC, cuya misión es controlar la financiación de las campañas electorales. Asimismo, estableció los límites a las contribuciones en favor de los candidatos y un tope máximo a los gastos para las elecciones legislativas y presidenciales.

La FECA se aplica a las elecciones al Congreso Federal y a la Presidencia del Gobierno Federal, es decir, sólo a una pequeña fracción de las elecciones que se desarrollan en Estados Unidos. Sin embargo, en el mismo periodo de su aprobación, la mayoría de los Estados adoptaron leyes parecidas que incluían una regulación bastante similar a la ley federal.

Sin perjuicio de que en próximos epígrafes se profundice más sobre esta cuestión, procede señalar que el 30 de enero de 1976, en Buckley v. Valeo, la Corte Suprema declaró inconstitucional todo límite impuesto a los gastos de los candidatos — con independencia de que éstos procedan de los fondos personales del candidato, de los fondos totales de la campaña o de grupos independientes - por ser contrario a la libertad de expresión consagrada en la Primera Enmienda de la Constitución. En este fallo, que constituía hasta $C$ i-

10 L. MEZZETTI: «Finanziamenti e condizionamenti del partito politico», XXIII Convegno dell'Associazione Italiana dei Costituzionalisti, Alessandria, 17 y 18 de octubre de 2008, pág. 3. Que efectivamente el modelo normativo estadounidense de financiación de las campañas electorales es un «modelo fundado sobre la disciplina diversificada y exhaustiva» lo ejemplifica que el propio texto de la Federal Election Campaign Law es una síntesis de tres leyes existentes en la materia con sus correspondientes enmiendas: Federal Election Campaign Act (FECA); Presidential Election Campaign Fund Act y Presidential Primary Matching Payment Account Act. A ellas se suma la Bipartisan Campaign Reform Act (BCRA). Así, en sus ciento sesenta y tres páginas de extensión nos encontramos ante previsiones normativas de excepcional y puntillosa precisión. Sirva de ejemplo el artículo 439 en el que se halla un elenco de los usos que son y que no son consentidos de los fondos recogidos por el candidato. O véase como el artículo 431 define quién debe ser considerado «candidato» a efectos de la ley, o qué incluye y qué no incluye términos como «contribución», «gasto», «fondos personales» del candidato $\mathrm{u}$ otros conceptos clave como «independent expenditures» o "generic campaign activity».

11 Federal Election Campaign Act de 1971 (Pub. L. No. 92-225, 86 Stat. 3). El resto de los procesos electorales, ya sean estatales o locales, se rigen por sus propias normas electorales, aunque la FECA actúa con carácter supletorio. FECA, sección 453. Las previsiones de la FECA en materia de financiación pública se hallan codificadas de forma separada, en el Internal Revenue Code. El texto completo de la ley tal y como quedó tal las enmiendas de 1974 se encuentra como apéndice de la Sentencia de la Corte Suprema Buckley v. Valeo, 424 U.S.1, 144-235 (1976). 
tizens la fuente de la jurisprudencia moderna en materia de financiación de las campañas electorales, la Corte Suprema vinculó «libertad de expresión» y «libertad de gasto» atendiendo a la fórmula «speech and money». Así, sostuvo que la imposición de cualquier restricción de gasto de capital destinado a la comunicación política por parte de una persona o grupo reduce necesariamente la capacidad de expresión. Sin embargo, el Tribunal Supremo mantuvo en este pronunciamiento la constitucionalidad de: por un lado, los límites de gasto previstos para las elecciones presidenciales en tanto que vinculados a la aceptación voluntaria de la financiación pública por parte de los candidatos; y, por otro, los límites impuestos a las contribuciones en orden a garantizar la protección de la integridad del sistema político frente a la corrupción aparente o real que pudiera surgir de aquéllas.

En definitiva, quedaban prohibidos los límites impuestos a los gastos que realizan los candidatos en su favor pero no la limitación de las contribuciones realizadas en favor del candidato.

A la luz de la citada sentencia, el Congreso tuvo que adecuar la legislación federal al parecer de la Corte y reformó la FECA en mayo de 1976, suprimiendo los topes máximos de los gastos en las elecciones legislativas. En 1979, otra ley añadió ulteriores modificaciones destinadas a simplificar los deberes de declaración sobre los recursos y gastos electorales que recaían sobre los candidatos.

En resumen, puede decirse que la FECA introdujo dos grandes novedades en este sector del ordenamiento norteamericano: la primera, relativa a la regulación de las «contribuciones» y la fijación de un umbral limitativo de los «gastos» electorales, y; la segunda, consistente en la introducción de una modalidad de financiación pública circunscrita a las campañas electorales presidenciales.

En la actualidad existen, pues, dos tipos o fuentes de financiación, una pública y otra, la más relevante, de naturaleza privada:

\section{LA FINANCIACIÓN PÚBLICA DE LAS CAMPAÑAS ELECTORALES}

Como se ha visto, las elecciones presidenciales son las únicas elecciones federales que cuentan con financiación pública ${ }^{12}$. De este modo, los candidatos a la presidencia reciben fondos del Gobierno Federal para cubrir parte de los gastos de sus campañas electorales, tanto en la fase previa de prenominación —en las elecciones primarias y caucusescomo en las presidenciales propiamente dichas; y los partidos políticos reciben fondos federales para la celebración de las convenciones nacionales en las que se procede a la elección de los candidatos del partido a la presidencia ${ }^{13}$.

Sin embargo, para poder acceder a los fondos públicos, los candidatos presidenciales y los comités de los partidos políticos que preparan las convenciones nacionales están obligados a obedecer los distintos requisitos que establece la Ley, entre los que destaca someterse a los límites de gastos electorales ${ }^{14}$. Se trata de una financiación pública facultativa y parcial.

El Departamento del Tesoro de los Estados Unidos crea el Presidential Election Campaign Fund, Fondo de Campaña para las Elecciones Presidenciales, PECF, con el que se efectúan

12 FECA, Internal Revenue Code, Presidential Election Campaign Fund Act, sección 9001 y ss.

13 FEC, Financiación pública de las elecciones presidenciales, 1994. 
progresivamente los pagos correspondientes a los candidatos y a los partidos políticos que cumplen con dichos requisitos legales ${ }^{15}$. Este Fondo se nutre exclusivamente de las aportaciones de los contribuyentes mediante la devolución de una porción de sus impuestos. Es decir, los contribuyentes, en el momento de la presentación de su declaración de la renta, pueden decidir que una parte de sus propios impuestos sea puesta a disposición del Fondo.

Los criterios o programas que presiden la distribución de los recursos que contiene el Fondo de Campaña son esencialmente tres:

- Primary Matching Payments o programa de desembolsos paralelos para las elecciones primarias: criterio según el cual, los recursos se atribuyen de cara a la nominación a aquellos precandidatos que en las elecciones primarias han sido capaces de obtener un montante de pequeñas donaciones individuales - no superiores a los 250 dólares por cada una de ellas - equivalente, al menos, a cinco millones de dólares por Estado, en veinte Estados distintos.

Los precandidatos que participan en las elecciones presidenciales primarias y que reúnan las condiciones legalmente establecidas, pueden recibir los fondos públicos denominados «desembolsos paralelos» (matching funds) ${ }^{16}$. De este modo, por cada $2.000 \$$ que reciba el precandidato por donaciones individuales, el Estado le concederá 250 \$ en concepto de «desembolso paralelo» ${ }^{17}$.

Los candidatos que deseen acceder a tales financiaciones deben declarar expresamente que quieren hacer uso del Fondo sólo y exclusivamente para los gastos electorales vinculados a la campaña electoral y que asumen, asimismo, el compromiso de respetar los límites de gasto prefijados. Tales límites varían en función de cada elección presidencial. Por ello, la mayoría de los precandidatos renuncian a los desembolsos paralelos, para no someterse a ningún tipo de límite en los gastos electorales ${ }^{18}$.

- El segundo de los programas de financiación pública está integrado por los llamados Party Convention Grants, en virtud de los cuales, los partidos políticos acceden a la contribución del Fondo para organizar sus propias convenciones nacionales — national conventions - en las que eligen a sus candidatos a la presidencia y vicepresidencia de los Estados Unidos ${ }^{19}$.

La FECA establece que tienen derecho a estas subvenciones los partidos políticos mayoritarios y todos los partidos políticos que hayan obtenido al menos un 5\% de los votos en las elecciones presidenciales anteriores. Sin embargo, las cantidades que se conceden a unos y a otros son diferentes, así, mientras los primeros reciben la cantidad de 4

14 A tenor de lo que establece la FECA en su sección 441.a.(b), ningún candidato a la presidencia de los Estados Unidos puede ingresar más de 10 millones de dólares durante las elecciones primarias, es decir, en la campaña para ser elegido el candidato a la presidencia por su partido, y otros 20 millones de dólares en la campaña para la presidencia.

15 Este fondo se integra exclusivamente por la donación tributaria de $3 \$$ (o hasta 6 \$ por declaración conjunta) que cada contribuyente haga voluntariamente al marcar la correspondiente casilla en su declaración de impuestos. FECA, sección 6096.

16 FECA, sección 9033.

17 FECA, sección 9034.

18 Así, de los 147 precandidatos que se registraron en la FEC en las últimas elecciones presidenciales, sólo ocho de ellos solicitaron desembolsos paralelos. http://www.fec.gov/

19 FECA, sección 9008. 
millones de dólares para la celebración de la convención, los partidos políticos minoritarios obtienen una cantidad inferior proporcional al número de votos que haya obtenido su candidato en las anteriores elecciones presidenciales.

- Por último, nos encontramos con los General Election Grants, atribuidos esencialmente a los candidatos nominados por los partidos políticos mayoritarios para cubrir los gastos de la campaña presidencial, siempre y cuando se comprometan a no superar el límite de gastos legalmente establecido y a no recaudar otros ingresos. Es decir, sólo podrán utilizar los fondos públicos asignados para su campaña y no podrá obtener ningún otro tipo de recursos.

En resumen, la legislación norteamericana establece una serie de límites y restricciones a los candidatos a la Presidencia que acceden a la utilización de la financiación proveniente del Fondo de Campaña para las Elecciones Presidenciales. Concretamente, los candidatos no pueden gastar más de cuanto reciben del Fondo, recibir contribuciones privadas ni utilizar fondos personales en cantidad superior a cincuenta mil dólares. Los candidatos deben, además, documentar los gastos realizados, manteniendo la contabilidad de los mismos y autorizando a la FEC para que realice las necesarias operaciones de supervisión. Y, en caso de violación de las diversas obligaciones prefijadas por la ley, el candidato se obliga a restituir los fondos recibidos en la cantidad fijada por la FEC $^{20}$.

\section{LA FINANCIACIÓN PRIVADA DE LAS CAMPAÑAS ELECTORALES}

Además de las fuentes de financiación pública anteriormente descritas, existen sustanciales formas de financiación privada dirigidas al sostenimiento de los partidos políticos y de las campañas electorales que son, de facto, las más cuantiosas y relevantes. El ordenamiento jurídico estadounidense contiene una exhaustiva regulación de tales fuentes de financiación privada destinada a evitar cualquier posible alteración de las normas de desarrollo de las elecciones federales.

Pueden distinguirse cuatro fuentes de financiación privada: las cuotas de los afiliados a los partidos políticos, que es una fuente de ingresos menor ${ }^{21}$; las donaciones a los candidatos o a los partidos, que constituyen la principal fuente de ingresos; los fondos personales del candidato; y los llamados «gastos independientes» —independent expenditures_- en los que se incluye toda donación que realizan las personas particulares para sufragar actividades de propaganda electoral a favor o en contra de un determinado candidato y que se

20 Es interesante observar que, en las elecciones primarias, se confirma una tendencia de los candidatos mayoritarios a renunciar a los fondos públicos, precisamente con el objetivo de sustraerse a los límites de gasto previstos por la ley. Naturalmente, una elección de este tipo permite gastar sin límites, pero comporta, al mismo tiempo, que la financiación de la campaña recaiga solamente sobre las espaldas del candidato que renuncia. Esto supone la participación de cientos de miles de personas, visto el límite muy bajo fijado por la misma normativa (no más de $\$ 2.000$ por persona).

21 Las cuotas de los afiliados son las cantidades que ingresa un partido político o un candidato por suscripciones regulares de los miembros del partido. Hay que señalar que en la tradición anglosajona no es habitual la existencia de un número elevado de afiliados a un partido político, por lo que la contribución que éstos hacen a la suma total de ingresos no es muy alta. K.H. NASSMACHER: "The funding of political parties in the Anglosaxon orbit», op. cit., pág. 36. 
hace independientemente de la campaña del candidato. Tales gastos independientes deben realizarse sin el conocimiento del candidato y no están sujetos a límite alguno desde el fallo de 1976 emitido en el caso Buckley v. Valeo de la Corte Suprema. Cada donante está obligado a llenar una declaración que especifique si el gasto fue hecho o no a favor del candidato y que certifique que fue realizado fuera de toda concertación con éste último. El dinero procedente de los «gastos independientes» sólo puede ser utilizado para campañas publicitarias, por ejemplo, para pagar la publicación en un periódico de un anuncio pidiendo el voto por un determinado candidato. A este respecto, la FECA exige que se publique una nota en el anuncio publicitario identificando a la persona que ha pagado por ella y que la publicación no ha sido autorizada por ningún candidato, esto es, que es «independiente» ${ }^{22}$. Los «independent expenditures» forman parte de lo que se conoce con el nombre de «soft money».

Por tanto, en el denominado «soft money» se incluyen los fondos personales, esto es, el patrimonio personal del propio candidato y los «gastos independientes». Ambos se destinan a la financiación de un candidato electoral, pero de manera indirecta y tienen en común que en ocasiones escapan al control de la FEC ${ }^{23}$.

Por otro lado, se encuentra el llamado «hard money», que incluye las cuotas de los afiliados y las donaciones entregadas directamente al candidato electoral, al partido, o al comité electoral del candidato, y que están sujetas a la fiscalización de la FEC ${ }^{24}$.

Las donaciones son la principal fuente de ingresos de que disponen los candidatos electorales y los partidos políticos. En este sentido, la FECA establece que cualquier ciudadano puede realizar donaciones, ya sean económicas o en especie, aunque prohíbe expresamente que cierto tipo de personas físicas o jurídicas puedan realizarlas en los procesos electorales federales. Así, los extranjeros, los sindicatos de trabajadores, los contratistas del gobierno federal y las empresas, tienen prohibido efectuar donaciones ${ }^{25}$. Sin embargo, paradójicamente, las empresas o los sindicatos pueden financiar indirectamente a los candidatos a través de la creación de los denominados Political Action Committees o Comités de Acción Política, PACs, que son comités reconocidos por la Ley y que tienen como finalidad primordial la de recabar fondos para apoyar a un determinado candidato, estando obligados a rendir cuentas de su actividad ante la llamada Federal Election Commission (FEC). Por lo tanto, si una empresa quiere financiar a un candidato basta con que cree un Comité de Acción Política de apoyo a ese candidato ${ }^{26}$, lo que ha sido considerado

22 FECA, sección 431 (17).

23 En la doctrina, vid., O.T. STEPHENS JR. yJ. M. SCHEB II, American Constitutional Law, 3.a ed., 2003, pág. 815; VVAA, «Recent legislation: Campaign Finance Reform», en 114 Harvard Law Review, 2000, pág. 2209; A. B. KRATENSTEIN: «Recent legislation: Campaign Finance Reform» en 36 Harvard Journal on Legislation 219, 221, 222, 1999; y E. J. DIONNE JR.: «Money and Elections», en The Washington Post, de 9 de abril de 2004, pág. 8.

24 Todo candidato debe constituir un comité electoral dentro de los 15 días siguientes a su declaración de candidatura. Este comité debe ser declarado y registrado por lo menos 10 días después de su constitución. Estará a cargo de la gestión de las contribuciones y gastos de los candidatos. El comité electoral elige un banco que es el único que podrá recibir y pagar los fondos. Los préstamos son considerados como contribuciones. Los informes detallados que rinden cuenta de las contribuciones y gastos de los candidatos deben llegar a la FEC (Federal Election Commission) para su control.

25 FECA, sección 441.b.(a).

26 FECA, sección 441.a (5). R. J. HREBENAR, M. J. BUR- BANK y R. C. BENEDICT, Political Parties, Interest Groups, and Political Campaigns, Boulder, Westview Press, 1999. 
por muchos como un subterfugio gracias al cual las empresas y otros sujetos colectivos pueden acceder a la condición de sujetos financiadores de las campañas electorales.

\section{El CONTROL DE LA FINANCIACIÓN DE LAS CAMPAÑAS ELECTORALES}

La Federal Election Campaign Act, FECA, establece que el acopio de fondos para las campañas electorales debe ser objeto de periódicas rendiciones de cuentas por parte de los candidatos, de los comités de los partidos y de los llamados PACs, especialmente registrados. Dicha rendición de cuentas o presentación de informes debe tener por objeto la exhaustiva descripción de todas las entradas y salidas de capital. Concretamente, el tesorero que es, en términos generales, el responsable de tal actividad, debe notificar inmediatamente cualquier contribución recibida cuyo montante supere los mil dólares y debe inserir en los informes periódicos un elenco que identifique a los sujetos que han otorgado contribuciones superiores a doscientos dólares al año. El candidato debe asimismo notificar los gastos propios que va a emplear. De fiscalizar el cumplimiento y aplicación de la legislación vigente se encarga la ya citada Federal Election Commmission $-F E C \longrightarrow{ }^{27}$.

Con la finalidad de moderar el importe de los gastos para las campañas electorales, el Congreso de los Estados Unidos modificó la Federal Campaign Act aprobando la llamada Bipartisan Campaign Reform Act, de 27 de marzo de 2002, comúnmente conocida con el nombre de su redactor, $M c$ Cain-Feingold ${ }^{28}$. Esta nueva ley fue aprobada con el objetivo de moderar el aumento del uso de los fondos soft money como fuente de financiación $y$, en consecuencia, prohíbe las contribuciones de dicha modalidad destinadas a financiar de manera ilimitada las actividades de los partidos más que las campañas electorales en sí mismas. De este modo, la reforma del 2002 introdujo una prohibición general para los partidos nacionales de recabar el llamado soft money, es decir, las contribuciones no reglamentadas procedentes de las empresas, de los sindicatos o de individuos particulares destinadas a sostener las actividades ordinarias, no las candidaturas a los cargos federales. Y ello porque, en la práctica, ésta vía se estaba convirtiendo en una laguna legal —loopbole - utilizada para evitar la severidad de las normas sobre la financiación de las campañas electorales ${ }^{29}$.

27 Se encuentra previsto un límite de dos mil dólares — duplicado por la BCRA, pues la FECA establecía un techo de mil dólares para donaciones de un sujeto individual; uno de veinticinco mil dólares para las donaciones dirigidas a los comités nacionales de partido; y uno de cinco mil dólares para las donaciones a los PACs (o cualquier otro comité de acción política, quizá independiente). Y, para los candidatos al Senado y a la Cámara de Representantes, existen mecanismos que permiten que el límite de los dos mil dólares se aumente si en su colegio electoral otro candidato gasta fondos propios en medida que supere un cierto límite.

28 Un estudio pormenorizado de la reforma introducida por la «Bipartisan Campaign Reform Act» puede verse en M. J. MALBIN: The Election alter reform: Money, politics and the Bipartisan Campaign Reform Act, Campaign Finance Institute Book, 2006. Asimismo, en materia de financiación electoral pueden verse: F. J. SORAUF: Money in American Elections, ScottForesman, 1988; y H. E. ALEXANDER: Financing Politics: Money, Elections and Political Reform, CQ PRESS, Cuarta Edición, 1992.

29 Para evitar que la nueva prohibición sea eludido, la ley establece otras prohibiciones a la provisión de fondos, al gasto del soft money en relación con los candidatos y cargas fderales y de los partidos estatales (estos últimos pueden recabar en un año contribuciones soft money no superiores a los $\$ 10.000$, pero no pueden gastarlos para actividades que influyan sobre las elecciones federales). En compensación se han doblado los límites del hard money. 
La otra laguna legal o loophole que permitía a los partidos y candidatos sortear los límites legislativos se concreta en la llamada c.d. issue advocacy, esto es, la actividad de comunicación radiotelevisiva sobre cuestiones específicas financiadas por grupos de interés diseñada para apoyar a un candidato concreto o para desaconsejar el voto hacia otro, o ambas cosas a la vez, pero que no utiliza fórmulas expresas y evidentes como «vota por...», «no votes por...» o similares. La reforma de 2002 ha creado una nueva categoría, la llamada Electioneering Communication, que exige la elaboración de informes y la publicidad de todos los gastos superiores a diez mil dólares destinados a financiar anuncios u otras emisiones de radio o televisión, por vía terrestre, cable o satélite, que hagan referencia a un «candidato claramente identificable» y se emitan treinta días antes de la celebración de unas elecciones primarias o en los sesenta días que preceden a las elecciones generales. Además, prohíbe expresamente a las sociedades y a los sindicatos financiar las comunicaciones electorales con fondos presupuestados ${ }^{30}$.

\section{LA JURISPRUDENCIA DE LA CORTE SUPREMA NORTEAMERICANA EN MATERIA DE FINANCIACIÓN DE LAS CAMPAÑAS ELECTORALES CON ANTERIORIDAD A DE CITIZENS UNITED}

En este sector del ordenamiento la doctrina jurisprudencial de la Corte Suprema se inicia con el caso Buckley v. Valeo, de $1976^{31}$. Como se ha anticipado anteriormente, en este caso la Corte enjuició la constitucionalidad de algunas disposiciones de la FECA, ley con la que el Congreso Federal trató de limitar la influencia corruptiva del dinero en las elecciones federales después del escándalo del Watergate. Dicha ley, a través de las enmiendas introducidas en su texto en el año 1974, restringía las contribuciones directas a favor de los candidatos y de los partidos políticos y la suma de dinero que unos y otros podían gastar. Para los demandantes, entre los que se encontraba el senador Buckley, tales restricciones resultaban incompatibles con la libertad de expresión consagrada por la Primera Enmienda de la Constitución.

30 «This term includes broadcast, cable, or satellite communications: (1) That refer to a clearly identified Federal candidate; (2) that are transmitted within certain time periods before a primary or general election; and (3) that are "targeted to the relevant electorate", that is, the relevant congressional district or State that candidates for the U.S. House of Representatives or the U.S. Senate seek to represent. Communications that refer to candidates for President or Vice-President do not need to be targeted to be electioneering communications. Those paying for the communications must meet certain disclosure requirements, and they cannot use funds from national banks, corporations, foreign nationals, or labor organizations to pay for the Communications: Federal Electoral Commission, Notice of proposed rulemaking en «Federal Register», Volume 67, núm. 152, agosto 7, 2002, pág. 1.

31424 U.S. 1 (1976). Buckley v. Valeo es una decisión per curiam (una decisión «de la Corte», pero no firmada por ninguno de sus miembros) de 138 páginas de extensión, la más larga de la historia de la Corte Suprema de los Estados Unidos. Cinco de los ocho Jueces Supremos elaboraron Votos Particulares, manifestando su disconformidad con uno u otro punto de la Sentencia. Véanse los siguientes estudios de la misma: D. D. POLSBY: «Buckley v. Valeo: The Special Nature of Political Speech», Supreme Court Review, 1976; A. NICHOLSON: «Buckley v. Valeo: The Constitutionality of the Federal Election Campaign Act Amendments of 1974», Wisconsin Law Review, 1977, págs. 323-325; y R. L. HASEN: «The Untold Drafting History of Buckley v. Valeo», 2 Election Law Journal, 2003, págs. 241 y ss. 
Con esta sentencia la Corte Suprema afirmó que la imposición de límites a los gastos de campaña de los candidatos — spenditures - , ya proviniesen de los fondos personales del candidato, de los fondos totales de la campaña o de grupos independientes, constituían una violación de los derechos establecidos en la Primera Enmienda constitucional, concretamente, de la libertad de expresión ${ }^{32}$. En cambio, sí declaró constitucionales los límites aplicados a las contribuciones - contributions - por estar justificados en orden a proteger la integridad del sistema político frente a la corrupción aparente o real que aquéllas pudieran provocar. De este modo, no cabía imponer límites a los gastos realizados por los candidatos en su favor pero sí a las contribuciones realizadas en favor del candidato.

La inconstitucionalidad de los límites impuestos a los gastos de campaña de los candidatos se basaba, en opinión de la Corte, en tres motivos: en primer lugar, en que la imposición de tales límites no es necesaria para impedir la «corrupción»; en segundo, que tales limitaciones constituyen una amenaza para la libertad de expresión; y, por último, que la finalidad que persigue la restricción legal, consistente en garantizar a todos los candidatos debidamente cualificados un acceso al público en condiciones de igualdad, no es causa suficiente para justificar cualquier forma de regulación que restrinja la libertad de expresión. A este último respecto las palabras del Tribunal Supremo son terminantes: "La idea de que el Gobierno puede restringir la expresión de algunos elementos de nuestra sociedad a fin de aumentar la voz relativa de otros es totalmente ajena a la Primera Enmienda» ${ }^{33}$.

Se observa que el punto del que parte el Tribunal Supremo es más que discutible, ya que equipara los gastos destinados a financiar las campañas electorales con un ejercicio típico de la libertad de expresión, y, en consecuencia, enjuicia la constitucionalidad de los límites imponibles a aquéllos mediante la aplicación del clásico strict scrutiny, test tradicionalmente empleado por la Corte para enjuiciar la constitucionalidad de los límites aplicados al ejercicio de un derecho fundamental.

En aplicación del «test de estricto escrutinio» la Corte considera inconstitucionales los límites impuestos a la libertad de expresión que derivan de la regulación de los gastos electorales salvo que aquéllos resulten imprescindibles para proteger un interés gubernamental imperativo. En palabras de la Corte: "Las limitaciones de gastos inciden en un ámbito de las actividades más fundamentales previstas en la Primera Enmienda. La discusión de los problemas públicos y el debate sobre los méritos de los candidatos forman parte del funcionamiento del sistema de gobierno establecido por nuestra Constitución (...). Los intereses del gobierno expuestos en apoyo de la Ley implican una supresión de la comunicación. Los intereses a los que la Ley sirve incluyen la restricción de voces de gente y de grupos que disponen de dinero para gastar (...). La Ley se dirige en parte a igualar la relativa capacidad de influencia en los resultados electorales de todos los votantes, estableciendo un techo a los gastos en expresión política de ciudadanos y grupos. (...) Cualquier restricción en la cantidad de dinero que una persona o grupo puedan gastar en comunicación política durante una campaña reduce necesariamente la cantidad de expresión, puesto que limita el número de

32 Gastos independientes son los que se hacen sin la cooperación de, o la consulta con, candidato alguno, ni con agente o comisionado autorizados del mismo, y sin acuerdo con, ni a petición o sugerencia de candidato alguno, ni de sus colaboradores autorizados. (U.S. Code, Vol. 2, Cap. 14, Secc. 431, 17).

33 Id. 48-49. 
problemas debatidos, la profundidad de su análisis y la dimensión de la audiencia a la que alcanza. (...). En suma, aunque las limitaciones de las contribuciones y de los gastos previstas en la Ley implican ambas intereses fundamentales de la Primera Enmienda, los topes en los gastos imponen restricciones más severas sobre las libertades protegidas de expresión politica y de asociación que las limitaciones de las contribuciones financieras».

Se observa cómo la Corte realiza una clara distinción: mientras los límites impuestos a las contribuciones de campaña sólo restringen marginalmente los derechos de la Primera Enmienda y, por tanto, deben ser sometidos un control judicial menos estricto «lower exacting scrutiny», los límites impuestos al gasto están sujetos a un control más estricto «strict scrutiny» porque limitan la libertad de expresión más directamente ${ }^{34}$.

Así, según la doctrina Buckley, mientras que la cantidad de contribuciones de campaña puede ser limitada para prevenir la corrupción o la aparición de la misma ${ }^{35}$, cualquier restricción aplicada al gasto independiente de cada persona o grupo no puede justificase en orden a salvaguardar el interés apremiante de evitar la corrupción, debido a la ausencia de un nexo causal. No existe, según la Corte, un vínculo directo entre el gasto independiente y la corrupción de candidatos: «La ausencia de predisposición y coordinación en un gasto a favor de un candidato o su agente no sólo socava el valor de los gastos para el candidato, sino que también alivia el peligro de que los gastos sean dados como un quid pro quo por compromisos inadecuados del candidato».

A la luz de Buckley se estableció una extraña forma de regulación que limita el modo con el que se puede obtener dinero, pero que deja intacto todo aquello que se puede hacer con él y establece, en consecuencia, una controvertida distinción entre «dar»y «gas$\operatorname{tar} »^{36}$.

En la misma línea desreguladora del gasto en materia de financiación de campañas electorales, se encuentra la Sentencia de la Corte Suprema pronunciada en el caso First National Bank of Boston v. Bellotti del año 1978. En ella, siguiendo la doctrina acuñada en Buckley, la Corte declaró inconstitucionales los límites aplicados a los gastos de campaña realizados por las empresas mercantiles para influir en el voto en supuestos de democracia directa, como refrendos o iniciativas legislativas — «limits on spending by corporations in ballot measure elections" ${ }^{37}$.

Cabe destacar que en Belloti el Juez Powell, autor de la opinión del Tribunal, afirmó que una empresa mercantil — corporation - es una persona a los efectos constitucionales y que, por lo tanto, debe ser tratada igual que cualquier otra persona natural cuando se planteen problemas relativos a la Primera Enmienda: «El valor inherente de la libre expresión en términos de su capacidad para informar al público no depende de la identidad de su fuente, de si se trata de una sociedad anónima, de una asociación, de una unión o de un individuo» ${ }^{38}$.

34 Id. At 20-21, 44-51.

35424 U.S. 1, 28-29 (1976) (per curiam).

36 S. ISSACHAROFF: «U.S.A.: Citizens united e il finanziamento dei partiti nel diritto americano», http://www.forumcostituzionale.it.

37435 U.S. 765, 767-70, 795 (1978).

38 Id. 777. 
En coherencia con su doctrina anterior, ocho años después, en el caso Federal Electoral Commission v. Massachusetts Citizens for Life ${ }^{39}$, la Corte sostuvo que las sociedades ideológicas sin ánimo de lucro, asociaciones — después llamadas «MCFL corporations»—, no pueden ver limitado los gastos procedentes de sus fondos de tesorería para apoyar la campaña de uno u otro candidato.

Sin embargo, procede señalar que en esta Sentencia, la Corte inicia un cambio de doctrina que se verá confirmado en su pronunciamiento posterior al sostener, en obiter dicta, que «el gasto directo que una empresa — corporation — destina a actividades políticas abre la posibilidad de que recursos amasados en el mercado económico puedan ser utilizados para proporcionar una ventaja injusta en el mercado político».

Dicho cambio de doctrina se ve confirmado en el precedente más directo de Citizens, el caso Austin v. Michigan Chamber of Commerce ${ }^{40}$, donde el Tribunal Supremo confirmó la constitucionalidad de una norma del Estado de Michigan que prohibía que las empresas dispusieran del fondo social general para contribuciones o gastos dirigidos a apoyar o a oponerse a los candidatos a puestos estatales electivos. Bien es cierto que, al mismo tiempo, la propia norma autorizaba ese tipo de desembolsos siempre que fueran con cargo a recursos segregados con esa finalidad — separate segregated funds-, a los cuales podían contribuir las personas que quisieran.

Y, aunque el Supremo admitió que la regulación estatal implicaba un cierto gravamen sobre los derechos de la Primera Enmienda de las corporations ${ }^{41}$, sostuvo que la ley estaba justificada para prevenir: «un tipo distinto de corrupción en la arena política: los efectos corrosivos y distorsionadores de las inmensas sumas de riqueza que se acumulan con la ayuda de la forma societaria y que tienen poca o ninguna correlación con el apoyo del público a las ideas políticas de la empresa» ${ }^{42}$.

Se observa como en Austin la Corte puso el énfasis en la prevención de la «distorsión» que los grandes gastos de las empresas podrían provocar sobre el proceso electoral, algo que el Supremo había rechazado en relación con los individuos en Buckley. De este modo, Austin reivindica el principio de igualdad en la financiación de las campañas electorales después de haber encontrado en el efecto «distorsionador» en las grandes acumulaciones de riqueza, constituidas por la mayor parte de las corporations, un tentativo de corrupción en la esfera pública.

En coherencia con lo dispuesto por la Corte en Austin, la restricciones aplicables a la capacidad de gasto corporativo para apoyar a candidatos políticos se halla presente tanto en la citada Ley Bipartisan Campaign Reform Act (BCRA) del 2002, también llamada McCain-Feingold, sobre restricciones en donaciones corporativas, como por el fallo de la Corte Suprema McConnell v. Federal Election Commission, resuelto en 2003.

39479 U.S. 238 (1986).

40494 U.S. 652 (1990).

41 El término corporations es empleado aquí como sinónimo de empresas, dado que es el término empleado en inglés.

$42 I d$. at 659-60. 


\section{CITIZENS UNITED V. FEDERAL ELECTION COMISSION: LA FINANCIACIÓN CORPORATIVA DE LAS CAMPAÑAS ELECTORALES ¿EJERCICIO DE LA LIBERTAD DE EXPRESIÓN DE LAS EMPRESAS?}

En Citizens United v. Federal Electoral Commission ${ }^{43}$ se plantea la constitucionalidad de la Bipartisan Campaign Reform Act (BCRA) del 2002, Ley que, como ha quedado expuesto, reforma la FECA prohibiendo la transmisión de cualquier mensaje televisivo television electioneering - financiado por las empresas y los sindicatos cuando aquél singularice e identifique a un candidato concreto para un cargo federal y sea emitido inmediatamente antes de las elecciones, concretamente, treinta días antes de la celebración de las elecciones primarias o sesenta días antes de las elecciones definitivas ${ }^{44}$.

Los hechos que han ocasionado el pronunciamiento más polémico de la Corte Suprema en las últimas décadas se remontan al período de las elecciones primarias de 2008, cuando una modesta organización sin ánimo de lucro, Citizens United, financiada con contribuciones empresariales, trató de emitir un documental despectivo sobre la entonces candidata demócrata Hillary Clinton. La Federal Election Commission declaró que la emisión de tal documental era ilegal por vulnerar la BCRA y la empresa Citizens United solicitó ser declarada exenta de la aplicación de la citada ley aduciendo que su intención era restringir la emisión del documental a un canal de pago. En enero de 2008, la empresa Citizens United emitió el documental Hillary: The Movie en cines de seis ciudades norteamericanas y en «Televisión bajo demanda» y se difundió en formato DVD y a través de Internet. La emisión del documental se produjo dentro del mes anterior a las elecciones primarias del partido Demócrata, lo cual vulneraba claramente la legislación federal vigente.

En la medida en que Citizens United había recibido donaciones empresariales para realizar el documental, trató de evadir la sanción de la FEC acudiendo al Tribunal del Distrito con el argumento de que los límites impuestos por la legislación vigente a este tipo de publicidad eran inconstitucionales al restringir la libertad de expresión. Concretamente, sostenía que la sección 441 b del Código de los Estados Unidos, que determina que las empresas no pueden contratar espacios publicitarios para apoyar a candidatos a puestos de elección popular federales, vulnera la Primera Enmienda constitucional. Sin embargo, la Corte de Distrito de Columbia negó la petición, por lo que el caso llegó en apelación a la Corte Suprema, la cual lo aceptó el 18 de agosto de 2008.

43558 U.S. 50 Citizens United v. Federal Electoral Commission (2010). El Magistrado Kennedy escribió la opinión mayoritaria de cinco Jueces en relación con la constitucionalidad de la imposición de límites a los gastos de las empresas para influenciar la elección de candidatos.

44 Citizens plantea un potencial conflicto con los artículos 201, 203 y 311 de la Bipartisan Campaign Reform Act of 2002 («BCRA»), Pub. L. No. 107-155, 116 Stat. 81 (2002), también conocida como la McCain-Feingold Act, que enmendó la Federal Election Campaign Act of 1971 («FECA»), Pub. L. No. 92-225, 86 Stat. 3, 1972. La ley sobre las elecciones federales se encuentra codificada en el Capítulo 14 Título 2 del United States Code (U.S.C.). Véase también el Federal Election Commission publication Federal Election Campaign Laws.

Section 203 of BCRA regulates the purchase of «electioneering communications.» Generally, these are «broadcast, cable, or satellite» communications made within 60 days of a general election or 30 days of a primary election. 2 U.S.C. $\S 434(f)(3)(A)(i)$ Section 203 restricts corporations and labor unions from funding electioneering communications from their general funds except under certain specific circumstances, e.g., get- 


\section{Citizens, una Corte Claramente Dividida}

A lo largo de más de un siglo, el ordenamiento jurídico norteamericano ha reconocido a las empresas — corporations - el estatus de «persona». Tal ficción se hizo necesaria para determinar en qué casos las llamadas corporations podían ser consideradas jurídicamente responsables o para individualizar las leyes de los distintos Estados aplicables a sus conductas. Sin embargo, sólo a partir de la reciente sentencia de la Corte Suprema emitida en el Caso Citizens United, aquéllas se han visto equiparadas a las personas físicas en lo que al ejercicio del derecho a la libertad de expresión se refiere, poniéndose fin a más de cien años de tradición legal que otorgaba a las empresas un régimen especial.

Es preciso recordar a este respecto que desde el año 1907, fecha en la que el Congreso aprobó la llamada Tillman Act a iniciativa del Presidente Theodore Roosevelt, ha sido generalmente asumido, incluso por la jurisprudencia de la Corte Suprema, que las corporations — que son sólo personas ficticias creadas por la ley- no gozan de los mismos derechos reconocidos por la Primera Enmienda constitucional en relación con la actividad política que las personas físicas. Este principio fue confirmado por el Tribunal Supremo en 1990, en el caso Austin v. Michigan Chamber of Commerce ${ }^{45}$, y legalmente ratificado en el año 2002, con la aprobación de la ya citada la Bipartisan Campaign Reform Act (BCRA), que prohibía a las empresas participar en campañas electorales televisivas antes de la celebración de las elecciones. Prohibición cuya constitucionalidad fue confirmada en el año 2003, en el caso McConnell v. Federal Election Commission (FEC ${ }^{46}$.

En la medida en que en Citizens la Corte Suprema no se limita a determinar la legalidad o ilegalidad de la retransmisión del documental Hillary: The Movie, sino que también evalúa la constitucionalidad de la norma que la prohíbe, procede a examinar la validez de los precedentes de Austin y McConnell, en los que sostuvo que es constitucionalmente válido impedir que las empresas apoyen directamente a algún candidato, ya que su riqueza puede influir las elecciones de manera inequitativa ${ }^{47}$.

La mayoría conservadora de la Corte - integrada por Chief Robert y Justices Samuel Alito, Anthony Kennedy, Antonin Scalia, y Clarence Thomas- reconoce que su

out-the-vote campaigns. 2 U.S.C. $§ 441 \mathrm{~b}(\mathrm{~b})(2)$ Permissible «electioneering communications» are subject to BCRA's disclosure and disclaimer requirements under sections 201 and 311.

Section 201 of BCRA contains a donor disclosure provision for electioneering communications. Persons who disburse an aggregate of $\$ 10,000$ or more a year for the production and airing of electioneering communications are required to file a statement with the Federal Election Commission (FEC). The statement must include the names and addresses of persons who have contributed in excess of $\$ 1,000$ to accounts funding the communication. 2 U.S.C. $\S 434(f)(1) \&(2)$.

BCRA's section 311 contains a disclaimer provision for electioneering communications. The entity responsible for the communication, if not authorized by the candidate or the candidate's political committee, must contain a statement that the organization «is responsible for the content of this advertising.» 2 U.S.C. $\S 441 \mathrm{~d}$.

45 Austin v. Michigan Chamber of Commerce, 494 U.S. 652 (1990).

46 540. U.S. 93, 126 (2003).

47494 U.S. 652 (1990). Con Citizens, la Corte Suprema revoca y parte de McConnell v. Federal Election Comm'n, 540 U.S. 93 (2003), que confirmó la constitucionalidad de la Section 203 of the Bipartisan Campaign Reform Act of 2002, 2 U.S.C. $\$ 441 b$. 
decisión es contraria a ambos precedentes judiciales, sin embargo, los entiende revocados sobre la base de los siguientes argumentos:

En primer lugar, sostiene que la sección 441b del Código de los Estados Unidos que determina que las empresas no pueden contratar espacios publicitarios para apoyar a candidatos a puestos de elección popular federales - tiene el potencial de desalentar el discurso público lo que determina la inconstitucionalidad de este precepto legislativo ya que la Primera Enmienda impide al Congreso Federal la aprobación de leyes que impidan o restrinjan la libertad de expresión. Y, sostiene la Corte: «aunque de acuerdo con la Ley las empresas pueden establecer Comités de Acción Política (CAP) para aportar dinero a las campañas políticas, éstos son una entidad distinta a la propia empresa, por lo que sí se impide la libertad de expresión de ésta última.

El supremo intérprete de la Constitución norteamericana afirma que no se puede discriminar a las empresas con base en su riqueza. A los individuos se les permite comprar espacios publicitarios para apoyar candidatos, y para hacerlo se requieren recursos económicos similares a los que utilizarían las empresas.

La sección $441 \mathrm{~b}$ hace distinciones arbitrarias, pues permite que los medios de comunicación (que muchas veces pertenecen a grandes empresas) puedan apoyar o atacar candidatos específicos.

Las aportaciones, incluso las de las empresas, no provocan corrupción ni percepción de corrupción. El hecho de que los representantes de las mismas puedan influir o relacionarse con cargos electos no significa que estos cargos sean corruptos. Asimismo, la percepción de influencia o de relaciones no harán que el electorado pierda fe en la democracia estadounidense.

El Juez Kennedy, en representación de la opinión mayoritaria de la Corte, sostiene que las decisiones de Austin y McConnell eran en sí mismas inconsistentes e incompatibles con la doctrina anterior de la Corte. Y considera que en Citizens el Tribunal se enfrenta «con dos líneas doctrinales en conflicto: la doctrina pre-Austin que prohíbe las restricciones al discurso político basadas en la identidad corporativa de quien ejerce su libertad de expresión; y una doctrina post-Austin, que las permite». De hecho, sostiene, «ninguna decisión anterior a Austin había sostenido que el Congreso careciese de la facultad de prohibir a las empresas el uso general de los fondos corporativos para influir en las elecciones».De este modo, la opinión mayoritaria de la Corte entiende que con Citizens se vuelve a la doctrina acuñada en el caso Buckley v. Valeo, de $1976^{48}$, en virtud de la cual, si bien el Congreso puede limitar la cantidad de las contribuciones privadas a las campañas políticas, a fin de evitar la corrupción o su «apariencia», no puede restringir, en ningún caso, lo que los particulares o las asociaciones puedan gastar en publicidad política «independiente».

Sin embargo, esto no es del todo cierto pues en Buckley la Corte permitió al Congreso imponer límites a las contribuciones privadas, algo que desaparece en Citizens. Ello implica, como ha señalado Ronald DWORKIN, que cualquier actuación del Congreso Federal que tratare a partir de ahora de regular los gastos de campaña de empresas y sindicatos podrá ser declarada inconstitucional ${ }^{49}$.

48424 U.S. 1 (1976).

49 R. DWORKIN: «The decision that threatens democracy», http://www.nybooks.com/articles/archives/2010/may/13/decision-threatens-democracy/. 
En relación con la doctrina del precedente, llama especial atención una de las razones aducidas por el Juez Kennedy para justificar la no sujeción de la Corte a la doctrina acuñada en Austin y en McConnell. Según el Magistrado, en representación de la opinión mayoritaria de la Corte, el carácter polémico de los pronunciamientos anteriores y la diferente composición actual del Tribunal justifican el cambio de doctrina, argumento del todo preocupante si se piensa que llevado a sus últimas consecuencias supondría el fin efectivo de la doctrina del stare decisis de la Corte Suprema.

Por lo que respecta a la opinión divergente, que fue redactada por el Juez John Paul Stevens, y a la que se adhirieron los Jueces Ruth Ginsburg, Stephen Breyer y Sonia Sotomayor, éstos son sus principales argumentos:

No es correcto tratar a las empresas como si fueran ciudadanos ya que sus recursos, intereses y manera de operar levantan sospechas sobre el impacto que puedan tener en el proceso democrático.

Con esta decisión se eliminan más de cien años de la tradición legal que otorga a las empresas un régimen especial, distinto al de los individuos.

Las discrepancias entre la opinión mayoritaria y los cuatro jueces disidentes son muchas y de gran calado. Sin embargo, el principal desacuerdo se plantea en torno a la cuestión de si existen intereses gubernamentales lo suficientemente relevantes como para justificar una mayor regulación y, en consecuencia, una restricción del discurso político de las empresas y de los sindicatos frente al de los individuos. A este respecto la opinión mayoritaria afirma que tales intereses nunca o rara vez van a existir, afirmando que la mayoría de las leyes que «identifican determinados oradores preferidos a expensas de los demás, son constitucionalmente sospechosas, y que, por tanto, la Primera Enmienda raramente permitirá restricciones al discurso político basadas en la identidad corporativa del orador o de quien expresa la opinión política».

En esta línea, la opinión mayoritaria rechaza todo argumento que pudiera justificar la prohibición impuesta por la BCRA a las «electioneering communications» de las empresas y de los sindicatos. Así, rehúsa la doctrina de la antidistortion empleada en Austin, según la cual, «existen intereses gubernamentales que justifican la selección del discurso corporativo para evitar los efectos corrosivos y distorsionadores que sobre la arena política pueden provocar las grandes acumulaciones de la riqueza». Un objetivo que la opinión mayoritaria reputa como la antítesis de los valores básicos consagrados por la Primera Enmienda. La mayoría también rechaza los argumentos basados en la necesidad de prevenir la corrupción quid pro quo.

La opinión disidente, en cambio, muestra un profundo desacuerdo con el razonamiento básico de la mayoría, llegando a acusar a ésta de ignorar la larga tradición del Derecho norteamericano que distingue entre las empresas y las personas físicas para muchos fines legislativos. Sin negar que «los intereses del Gobierno puede ser más o menos relevantes en relación con los diferentes tipos de oradores», los jueces disidentes sostienen que «las especiales características de la estructura corporativa requieren de una regulación especialmente cuidadosa en el contexto electoral».

Los jueces discrepantes defienden la doctrina acuñada en McConnell, derivada de Austin, según la cual, las limitaciones impuestas a las actividades de campaña de las empresas y sindicatos encuentran justificación en la necesidad de «preservar la integridad del 
proceso electoral, prevenir la corrupción, sostener la responsabilidad activa y alerta del ciudadano y mantener la confianza de éste en el Gobierno».

\section{Citizens y las Teorías sobre la Primera EnMienda de la Constitución AMERICANA: UN DIFÍCIL ENCAJE}

Adoptada en diciembre de 1791, la Primera Enmienda es una de las piezas fundamentales del Derecho Constitucional norteamericano. A partir de las menos de cincuenta palabras contenidas en ella, el Tribunal Supremo de los Estados Unidos ha sabido construir una doctrina riquísima garante de las libertades civiles fundamentales, muy especialmente de las libertades religiosa, de prensa, de asociación y de expresión ${ }^{50}$.

La textura abierta de la Primera Enmienda de la Constitución norteamericana se hace evidente en el carácter abstracto de su tenor. Como las más importantes previsiones constitucionales, la misma garantiza el «derecho» a la libertad de expresión pero no especifica las dimensiones del mismo. Es preciso, por tanto, acudir a la interpretación constitucional para determinar su alcance.

En Citizens, la Corte Suprema americana ofrece una visión absolutista de la Primera Enmienda de la Constitución que permite a las empresas gastar sumas ilimitadas de dinero de manera independiente para apoyar u oponerse a candidatos para el cargo. En lo que afirma ser una firme defensa de la «libertad de expresión», consagrada por la Primera Enmienda constitucional, la Corte Suprema da carta blanca a la desregularización de la financiación de las campañas electorales, permitiendo a las contribuciones opacas de las empresas, sin límite de ningún tipo.

Una de las teorías interpretativas de la Primera Enmienda a la que apela el Juez Kennedy, en representación de la mayoría, es la que otorga a la libertad de expresión en la arena política un carácter imprescindible para «la existencia de un electorado informado», pero lo hace de manera poco convincente.

Es sabido que la conformación de lo que el Juez HOLMES ha dado en llamar un «free marketplace of ideas ${ }^{51}$,» implica que la libertad de expresión política es una condición imprescindible para la existencia de un efectivo sistema democrático porque garantiza que los votantes tengan acceso al más amplio y diverso abanico de información y opinión política posible. Pues bien, en Citizens, la opinión mayoritaria no ofrece un razonamiento sólido que justifique que permitir a las corporations intervenir en las elecciones pueda generar la conformación de una sociedad más informada. Antes al contrario, como sostiene DWORKIN, las corporations no tienen ideas propias y los anuncios por ellas financiados es lógico que promuevan las opiniones de sus directores, que pueden publicarlas o difundirlas por sí mismos o con otras personas de ideas afines a través de los Comités de Acción Política (PACs).

50 «El Congreso no hará ley alguna con respecto a la adopción de una religión o prohibiendo el libre ejercicio de dichas actividades; o que coarte la libertad de expresión o de la prensa, o el derecho del pueblo para reunirse pacíficamente, y para solicitar al gobierno la reparación de agravios».

51 X. WANG: «Freedom of Speech» in the United States Constitution», Perspectives, Vol. 2, núm. 5, abril, 2001, http://www.oycf.org/Perspectives2/11_043001/Contents.htm. 
En este sentido, la opinión mayoritaria de la Corte defiende que la financiación publicitaria de las empresas en las campañas electorales contribuye a la difusión de opiniones de interés público. Sin embargo, tal afirmación parece contradecir la máxima según la cual los administradores de las empresas están legalmente obligados a emplear los fondos de éstas para promover exclusivamente los intereses financieros corporativos, que, difícilmente pueden coincidir con el interés común ${ }^{52}$. La argumentación de la mayoría de la Corte se reputa endeble desde este punto de vista, pues, si las empresas ejercen las facultades que aquélla les atribuye en Citizens, pudiendo comprar una elevada cuota de tiempo de emisión televisiva para emitir publicidad política, su campaña electoral puede minar la educación política de los ciudadanos en lugar de mejorarla.

La segunda gran teoría en torno a la Primera Enmienda constitucional, se centra en el papel relevante que posee la libertad de expresión para proteger el estatus, la dignidad y el desarrollo moral de los ciudadanos en igualdad de condiciones en el proceso político. De acuerdo con esta segunda teoría, los intereses protegidos por la Primera Enmienda son, única y exclusivamente, los intereses morales de los individuos físicos que pudieran ver vulnerada su dignidad si su libertad de expresión se viese censurada. A ello se refiere el magistrado John Paul Stevens en su extensa y sólida opinión disidente a la Sentencia, suscrita por los jueces Stephen Breyer, Ruth Ginsburg, y Sonia Sotomayor, cuando afirma que «uno de los fines fundamentales de la Primera Enmienda es la protección de la propia expresión del individuo». Extender la libertad de expresión a las corporations sobre la base de esta segunda teoría, como trata de hacer el relator de la Sentencia, el Juez Kennedy, implica atribuir a las empresas la titularidad de valores tan intrínsicamente vinculados a la idea de naturaleza humana como el valor dignidad.

La tercera teoría ampliamente aceptada en torno a la Primera Enmienda de la Constitución norteamericana, radica en el papel fundamental que la libertad de expresión juega para garantizar la honestidad y la transparencia en el Gobierno. Y ello porque, si el Ejecutivo gozase de plena capacidad para censurar las críticas recibidas o para limitar el derecho a la libertad de prensa, también consagrado en la Primera Enmienda, la corrupción institucional camparía a sus anchas. A este respecto, la opinión mayoritaria de la Corte sostiene que «si la Primera Enmienda fuese interpretada para permitir que el Congreso prohíba a las corporations hacer publicidad en las campañas electorales, ello otorgaría también a aquél la capacidad de prohibir los anuncios de los diarios o periódicos que son propiedad de aquéllas».

Sin embargo, cabe rebatir este argumento teniendo en cuenta que el tenor de la Primera Enmienda singulariza explícitamente la libertad de prensa con respecto a la libertad de expresión en general y que el Tribunal Supremo siempre ha aceptado que una prensa libre es indispensable para la existencia de un buen gobierno, lo cual no quiere decir, en ningún caso, que ello requiera la extensión de la segunda a las empresas ordinarias.

52 Véase a este respecto T. W. JOO, The Modern Corporation and Campaign Finance: Incorporating Corporate Governance Analysis into First Amendment Jurisprudence, 79 WASH. U.L.Q., Abril, 2001. 
$* * *$

TITLE: Citizens united and the electoral campaign financing in the American Law

ABSTRACT: With the ruling of the U.S. Supreme Court, pronounced in the case Citizens United v. Federal Election Commission, February 2010, the American Supreme Court has overturned a ruling that for twenty years imposed limits and restricted the ability of firms and unions to finance the election campaigns of political parties in federal elections. This decision of the Supreme interpreter of the U.S. Constitution was a radical upheaval in the U.S. election as the ruling nullifies twenty years ago in Austin v Case. Michigan Chamber of Commerce, according to which companies could have limited the use of their funds for political purposes to avoid the risks of corruption. Citizens offers an absolutist view of the First Amendment of the Constitution that allows companies to spend unlimited amounts of money independently to support or oppose candidates for office, giving carte blanche to the deregulation of the financing of election campaigns and allowing contributions opaque firms without any limit.

RESUMEN: Con la sentencia de la Corte Suprema norteamericana, pronunciada en el Caso Citizens United v. Federal Electoral Commission, de febrero de 2010, el Tribunal Supremo Norteamericano ha revocado un fallo que desde hacía veinte años imponía límites y restringía la capacidad de las empresas y los sindicatos para financiar las campañas electorales de los partidos políticos en las elecciones federales. Esta reñidísima decisión del Supremo intérprete de la Constitución estadounidense, ha supuesto una auténtica convulsión en materian electoral en los Estados Unidos pues anula el fallo emitido veinte años atrás en el Caso Austin v. Cámara de Comercio de Michigan, según el cual, las empresas podían ver limitado el uso de sus fondos con fines políticos para evitar los riesgos de corrupción.Citizens ofrece una visión absolutista de la Primera Enmienda de la Constitución que permite a las empresas gastar sumas ilimitadas de dinero de manera independiente para apoyar u oponerse a candidatos para el cargo, dando carta blanca a la desregularización de la financiación de las campañas electorales y permitiendo a las contribuciones opacas de las empresas sin limite de ningún tipo.

Key Words: Democratic Principle, Freedom of expression, System of financing the political parties.

Palabras Clave: Palabras clave: Principio democrático, Libertad de expresión, Sistema de financiación de los partidos políticos.

FECHA DE RECEPCIÓN: 01.12.2011 FeCHA DE ACEPTACIÓN: 19.07.2012

UNED. Teoría y Realidad Constitucional, núm. 30, 2012, pp. 433-453. 